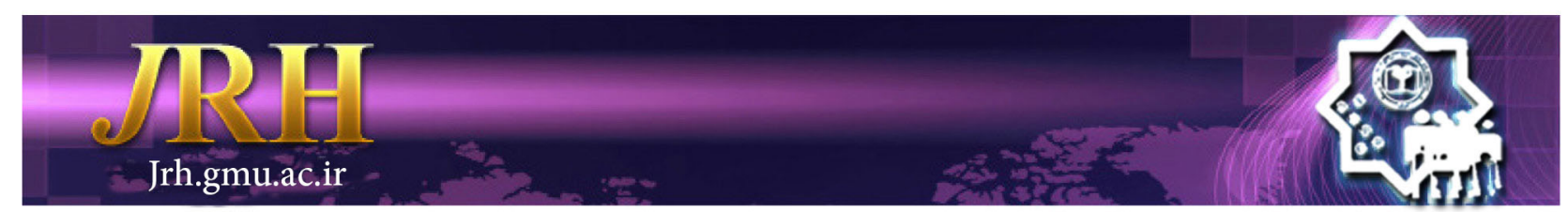

\title{
Determinants of daily exercises among employees with overweight or obesity: the application of health belief model
}

\author{
Reza Jorvand ${ }^{1}$, Kazmieh Sadeghirad ${ }^{2}$, Ali Asghar Haeri Mehrizi ${ }^{3}$, \\ Fazlollah Ghofranipour ${ }^{4}$, Mahmoud Tavousi ${ }^{3}$
}

\author{
Journal of Research \& Health \\ Social Development \& Health Promotion \\ Research Center \\ Vol. 9, No. 5, Sep \& Oct 2019 \\ Pages: $387-393$ \\ DOI: $10.29252 /$ jrh.9.5.387 \\ Original Article
}

\begin{abstract}
1. Department of Public Health, School of Health, Ilam University of Medical Sciences, Ilam, Iran

2. Department of Nursing Community Health, School of Nursing, Ilam University of Medical Sciences, Ilam, Iran

3. Health Metrics Research Center, Iranian Institute for Health Sciences Research, ACECR, Tehran, Iran

4. Department of Health Education \& Health Promotion, Faculty of Medical Sciences, Tarbiat Modares University, Tehran, Iran

Correspondence to: Mahmoud Tavousi, Health Metrics Research Center, Iranian Institute for Health Sciences Research, ACECR, Tehran, Iran

Email: Tavousi@acecr.ac.ir
\end{abstract}

Received: 25 Mar 2018

Accepted: 19 Dec 2018

How to cite this article: Jorvand R, Sadeghirad K, Haeri Mehrizi AA, Ghofranipour F, Tavousi M. Determinants of daily exercises among employees with overweight or obesity: the application of health belief model. $J$ Research Health2019; 9(5): 387- 393.

\begin{abstract}
The obesity is increasing as one of the risk factors of CVD among high classes in developing countries. This study aimed to identify the determinants of daily exercises among overweight or obese employees using the Health Belief Model (HBM) in 2017. For the purpose of the study, 101 employees working in healthcare facilities affiliated with Ilam University of Medical Sciences were included after presenting a written consent form. The tool to collect data was a self-made questionnaire, which was applied after reviewing and approving its validity and reliability. The results showed that the mean of daily exercises among participants was $8.22 \pm 1.19$ min. Statistical tests showed that there was a significant relationship between gender and the amount of daily exercises so that the mean exercises of men was higher than that of women. Accordingly, self-efficacy was determined as the strongest predictor of daily exercises based on multiple linear regression tests. At the end of the study, the researchers concluded that amount of daily exercises among the participants of this study was low while overweight and obesity would increase the risk of cardiovascular diseases; therefore, applying appropriate interventions, based on HBM in particular, can be effective in reducing the risk of obesity.
\end{abstract}

Keywords: Exercises, Overweight, Obesity, Government Employees

\section{Introduction}

About $70 \%$ of diseases result from inactivity and having low activity is one of the ten main causes of death around the world, resulting in about two million deaths annually [1,2]. In developing countries such as Iran, death caused by Cardiovascular Diseases (CVD) has reached 35 to $40 \%$ and this increase could be dangerous because it is the result of a decrease in physical activity, weight gain, an increase in blood lipids and other risk factors [3]. The recommended period for exercises in order to reduce the risk of CVD among adults is 30 minutes with moderate intensity in all the week or at least 5 days a week [4,5].

The results presented about the prevalence of inactivity and low mobility in Iran are different, depending on the tools, techniques, methodologies, and the target population, but most studies have reported a high prevalence of physical inactivity [6]. For example, based on the findings of the third phase of the national surveillance of risk factors for non-contagious 
diseases, the prevalence of physical inactivity among adults was $40 \%$ [7] and the prevalence of inactivity in Ilam province was $28 \%$, according to national studies [8].

In other studies, the prevalence of inactivity among employees in Isfahan university of medical sciences was reported as 68\% [9] and among employees in Hamadan university of medical sciences as $65 \%$ [10]. Jalilian in a study conducted on the employees in Ilam university of medical sciences, based on a meta-theoretical model, reported that $99 \%$ of the participants were in the pre-contemplation, contemplation, and preparation stages that all indicate inactivity among these subjects [11]. In another study, $68.16 \%$ of teachers who participated in the study in Dehloran [12] were inactive and had a tendency to be sedentary.

A sedentary lifestyle increases the risk of obesity by $2-5$ times $[1,2]$. The obesity is increasing as one of the risk factors of CVD [13] among high classes in developing countries [14].

The system taking care of risk factors for non-contagious diseases reported in 2009, by studying people aged $15-64$ years old, that $44 \%$ of the participants were overweight or obese and $52.9 \%$ of people aged $45-64$ years old in the country simultaneously had at least three out of five risk factors (daily smoking, low intake of fruits and vegetables, Inactivity, Overweight and obesity, and High blood pressure) for CVD and in other words, they were at a high risk [15].

To cope with obesity that its dimensions are expanding day by day, appropriate methods should be found [16]; making changes in health behaviors is the best way to decrease diseases and mortalities and improve the quality of life and understanding predictive factors of behavior would facilitate the intervention in line with changing behaviors [17]. One of the patterns designed to explain health behaviors and used by researchers is the Health Belief Model (HBM).

This model explains the quality of changing behavior in relation to the health of people and helps educators to evaluate and describe health behaviors of people through understanding their beliefs [18]. Since planning for implementing educational interventions should be done based on facts and commensurate with features of various groups [19], the research team decided to evaluate determinants of daily exercises among employees with overweight and obesity who were working in one of the healthcare systems of Ilam university of medical sciences using HBM in order to use the results to design interventions.

\section{Method}

This cross-sectional study was conducted on employees in one of the healthcare systems covered by Ilam university of medical sciences during the second half of 2016. The inclusion criteria were being a permanent or nonpermanent employee, lack of chronic diseases or diseases causing motor limitations, having Body Mass Index (BMI) equal to or higher than 25 , and filling an informed consent form. The sample size was determined as 161 participants with 276 employees, 95\% confidence interval, $\mathrm{p}=\mathrm{q}=50 \%$, and $\mathrm{z}=1.96$ using the Cochran formula. The sampling was done by referring to the workplace of the employees and using simple random sampling method (according to the lists of the employees). Eventually, 169 employees completed the questionnaires and 101 participants who had a BMI over 25 were enrolled.

The tool to collect data in this study was a threepart questionnaire. The first part was to gather the participants' demographic information (including age, gender, marital status, education, work experience, job category, and history of cigarette smoking, hookah and so on); in the second part, the standard questionnaire of Impact of Sport on the Cardiovascular diseases Scale based on the Health Belief Model (HBMISCS) was used [20]. This questionnaire contains questions based on the constructs of perceived susceptibility, perceived intensity, perceived benefits, perceived barriers, and selfefficacy; scoring this questionnaire is based on a five-point Likert scale in which the score one is for the weakest response and the score five is for the best answer. The questionnaire of HBMISCS has been designed to assess participants' health beliefs about the effects of exercise on 
cardiovascular diseases. The reliability of these tools was confirmed using Cronbach's alpha in various constructs as 0.715 to 0.816 .

The third part consisted of questions related to behavior and body mass index. Three items were used to measure daily exercise (with yes/ no answers) and daily and weekly exercise duration in terms of minutes. In this study, daily exercise was measured using the self-reporting questionnaire.

In the present study, BMI was used to determine the overweight and obesity. Determining BMI is one of the most common anthropometric methods for diagnosis of obesity, defined as weight divided by height squared $\left(\mathrm{Kg} / \mathrm{m}^{2}\right)$ $[21,22]$. Accordingly, people with BMI of less than 25 are normal, $25<\mathrm{BMI}<30$ are overweight, and over 30 are obese [23]. In this study, measuring BMI was considered as the criterion of measuring obesity. Measuring height was done using a height gauge model with an accuracy of one millimeter while standing, without shoes, and the back of the feet, the buttocks, the scapula and the back of the head were in contact with the vertical surface. Measuring weight was done using a digital scale model with the accuracy of $0.1 \mathrm{Kg}$ without shoes and with the least clothes. All measurements were done by the same person and the same scale; Then, BMI of people was calculated and recorded in their questionnaires. The assumption of the researcher in this study was the relationship between the constructs of the health belief model and the exercises behavior, as well as the ability to predict the behavior of exercises by the construct of the health belief model.

Many studies have shown that the regression technique is robust against the assumption that data are normal [24]; therefore, this technique was used in this study. In order to decide about the existence of the relationship, a p-value of less than 0.5 was the criterion of judgment. To analyze data obtained in this research, SPSS-16 was used. Data were analyzed using statistical tests of Pearson correlation, multiple linear regression analysis, and other tests (as appropriate). In addition, to being committed to keeping the personal information and the name of studied cities confidential, the research team received the necessary ethics approvals from the research council and the medical ethics committee of the medical school of Tarbiat Modares University under code no. IR.TMU. REC.1394.148. The informed consent form was obtained from all participants.

\section{Results}

The study results showed that $57.43 \%$ of the participants were men and $86.14 \%$ were married; meanwhile, $56.44 \%$ had a bachelor degree and $63.37 \%$ did not daily exercises. The mean of participants' age in this study was

Table 1 Demographic characteristics of participants $(N=101)$

\begin{tabular}{lcccc}
\hline & & Mean \pm SD & $\mathrm{N}$ & $\%$ \\
\hline Age & & $38.47 \pm 4.53$ & & \\
\hline Exercises (Daily) & & $8.22 \pm 1.19 *$ & & \\
\hline Exercises (Weekly) & Male & $35.94 \pm 3.95 *$ & & \\
\hline \multirow{2}{*}{ Gender } & Female & 58 & 57.43 \\
& Single & 43 & 42.57 \\
\hline \multirow{2}{*}{ Marital status } & Married & 14 & 13.86 \\
& Yes & 87 & 86.14 \\
\hline \multirow{2}{*}{ Exercises (Daily) } & No & 37 & 36.63 \\
& Diploma degree & 64 & 63.37 \\
\hline \multirow{2}{*}{ Education } & Associate's degree & 13 & 12.87 \\
& Bachelor's degree & 19 & 18.81 \\
& Master's Degree & 57 & 56.44 \\
\multirow{2}{*}{ BMI } & $30>$ BMI $>25$ & 12 & 11.88 \\
& $35>$ BMI $>30$ & 82 & 81.19 \\
*Minutes & BMI $>35$ & 15 & 14.85 \\
& & 4 & 3.96 \\
\hline
\end{tabular}


$38.47 \pm 4.53$ years, $81.19 \%$ were overweight, and $14.85 \%$ had obesity type I.

In this study, the means of daily and weekly exercises were $8.22 \pm 1.19$ and $35.94 \pm 3.95$ min, respectively, that were low compared to the standard value (30 minutes a day for the whole week or at least 5 days a week). In this study, only 37 participants $(36.6 \%)$ did a daily exercises and 64 participants $(63.4 \%)$ did not exercises on a daily basis.

Reviewing the results showed that there was no statistically significant relationship between marital status and daily exercises; however, mean and standard deviation of daily exercises was significantly higher in single than in married individuals, but there was a significant relationship between gender and the amount of daily exercises, and the mean of daily exercises in men and women Were 9.40 \pm 12.67 and $6.63 \pm 10.63 \mathrm{~min}$, respectively, and there was a statistical difference. Moreover, there was no significant relationship between the amount of daily exercises and education.

The relationship between the constructs of the health belief model and the daily exercises behavior was evaluated using Pearson correlation coefficient (Table 2), and predictive constructs for daily exercises behavior were determined using multiple enter method regression (results in Table 3). In

Table 2 Pearson correlation between the daily exercises and health belief model structures among participants

\begin{tabular}{|c|c|c|c|c|c|c|c|}
\hline \multirow[b]{2}{*}{ Independent variables } & \multirow[b]{2}{*}{ Mean \pm SD } & \multicolumn{6}{|c|}{ Pearson correlation } \\
\hline & & $\begin{array}{c}\text { Exercises } \\
\text { (Daily Time) }\end{array}$ & Susceptibility & Severity & Benefits & Barriers & Self-efficacy \\
\hline Exercises (Daily Time) & $8.22 \pm 1.19$ & 1 & & & & & \\
\hline Perceived susceptibility & $9.60 \pm 0.83$ & 0.080 & 1 & & & & \\
\hline Perceived severity & $22.69 \pm 2.21$ & $0.322 * *$ & $0.229 * *$ & 1 & & & \\
\hline Perceived benefits & $22.78 \pm 2.56$ & $0.211^{*}$ & $0.238^{*}$ & $0.452 * *$ & 1 & & \\
\hline Perceived barriers & $9.08 \pm 3.12$ & 0.069 & 0.032 & 0.025 & 0.017 & 1 & \\
\hline Self-efficacy & $20.69 \pm 3.9$ & $0.309^{* *}$ & 0.133 & $0.295^{* *}$ & $0.735^{* *}$ & $0.206^{*}$ & 1 \\
\hline
\end{tabular}

$*$ Sig. $=\mathrm{p}<0.01 * *$ Sig. $=\mathrm{p}<0.05$

Table 3 Multiple linear regression coefficients of independent variables to predict daily Exercises

\begin{tabular}{lccccccc}
\hline & \multicolumn{2}{c}{$\begin{array}{c}\text { Unstandardized } \\
\text { coefficients }\end{array}$} & & \multirow{2}{*}{ Beta } & T & Sig. & \multicolumn{2}{c}{ Collinearity Statistics } \\
\cline { 2 - 3 } & B & Std. Error & & & & Tolerance & VIF \\
\hline Constant & -31.828 & 16.352 & & -1.946 & 0.055 & & 1.087 \\
Perceived susceptibility & 0.142 & 1.401 & 0.010 & 0.101 & 0.920 & 0.920 & 1.286 \\
Perceived severity & 1.619 & 0.570 & 0.301 & 2.840 & 0.006 & 0.777 & 2.679 \\
Perceived benefits & -0.910 & 0.710 & -0.196 & -1.282 & 0.203 & 0.373 & 1.093 \\
Perceived barriers & -0.043 & 0.372 & -0.011 & -0.115 & 0.908 & 0.915 & 2.393 \\
Self-efficacy & 1.115 & 0.441 & 0.366 & 2.529 & 0.013 & 0.418 & \\
\hline
\end{tabular}

Sig. $=\mathrm{p}<0.05$, a: Dependent Variable: daily Exercises

Table 4 Model Summary and related statistical quantities

\begin{tabular}{ccccc}
\hline \multicolumn{3}{c}{ Model Summary } & \multicolumn{2}{c}{ ANOVA } \\
\hline Model & $\mathrm{R}$ & R Square & $\mathrm{F}$ & Sig. \\
\hline 1 & $0.411^{\mathrm{a}}$ & 0.169 & 3.862 & $0.003^{\mathrm{b}}$ \\
\hline
\end{tabular}

a. Predictors: (Constant), self-efficacy, perceived susceptibility, perceived barriers, perceived severity, perceived benefits

b. Dependent Variable: P2

Table 4, a summary of the model and related statistical quantities is presented.

The results of the study showed that there is a significant relationship between the variable of behavior (amount of daily exercises) and variables of perceived severity, perceived benefits, and self-efficacy (Table 2). The results of multiple regression indicated 
that perceived severity and self-efficacy are significant predictors of the amount of daily exercises $(\beta=0.301$ and $\beta=0.366)$ among the participants of this study (Table 3 ). In this analysis, the predictive variables were perceived susceptibility, perceived severity, perceived benefits, perceived barriers, and selfefficacy; and the correlation coefficient was 0.411 and the coefficient was 0.169 .

\section{Discussion}

According to the results of multiple linear regression tests, self-efficacy was determined as the strongest predictor of daily exercises.

According to the results of multiple linear regression tests, self-efficacy was determined as the strongest predictor of daily exercises.

In fact, by removing or reducing the risk factors for CVD, over $80 \%$ of these diseases can be prevented. Some of these risk factors such as inadequate physical activity are modified by changes in the environment and changes in behavior or lifestyle of people [15]. The obesity phenomenon is increasing among employees due to the sedentary style [25] and it is anticipated that obesity will be the first cause of the decrease in life expectancy in the next 100 years [26]. In the present study, $50.31 \%$ of the participants were overweight and $11.66 \%$ were obese which was almost consistent with the results of a study by Abdi [25]. In that study, the rate of overweight and obesity was estimated at $45 \%$ and $14 \%$, respectively; and there was no significant relationship between the amount of daily exercises and BMI.

In the present study, there was a significant positive correlation between the constructs of perceived severity, perceived benefits, and self-efficacy. Multiple linear regression analysis indicated that in this study, there was a significant relationship between daily exercises and self-efficacy and perceived severity; but self-efficacy was the strongest predictor of daily exercises among employees who participated in the study; In the study by Rahimi and colleagues [27], perceived susceptibility, perceived severity, and self-efficacy were the three predictors of preventive behavior for
CVDs among women who went to the health care centers in Qom. In other studies [2830], there was also a significant relationship between perceived benefits and exercises. In the study by Sullivan [30] and Vahedian [31], among HBM constructs, self-efficacy and perceived benefits had the most predictive power concerning physical activity.

In the study by Hate Nia, the results of logistic regression analysis determined self-efficacy as the significant predictor of exercises behavior and these findings are consistent with the results of a study by Soleimanian [32] where self-efficacy was recognized as the most important predictor construct of physical activity behavior and the results of study of Vahedian Shahroudi [33] and Johnson [34] studies where they reported self-efficacy as the most powerful predictor of physical activity behavior.

Bandura [35], who introduced the concept of self-efficacy for the first time, believed that self-efficacy is one of the main predictors of behavior. In this study, self-efficacy was the strongest predictor of daily exercises. The role of self-efficacy is so necessary for changing behavior and in most other similar studies, self-efficacy was positively and significantly associated with improving physical activity [36]. Self-efficacy makes an individual feel the ability to do the healthy behavior (daily exercise and physical activity); this can help an individual to continue that behavior, which has begun because of understanding the risk of cardiovascular diseases. In this study, the perceived intensity and self-efficacy were the strongest predictors of daily exercise among employees who were overweight or obese, meaning that perceived intensity (the sense of danger) resulted from cardiovascular disease could only cause the beginning of exercises and self-efficacy led to the continuation of this behavior in long term.

Limitations of this study were the low sample size and measuring both HBM constructs and the amount of daily exercise based on self-reporting rather than using an objective yardstick which may increase the rate of 
human errors.

\section{Conclusion}

The present study showed that the amount of daily exercises among participants was low remarkably compared to the standard level while overweight and obesity increase the risk of CVD. Thus, it is necessary to implement appropriate educational interventions to improve this situation and the findings of this study can be used for the design of appropriate interventions.

\section{Acknowledgment}

The researchers thank all employees participating in the study.

\section{Authors' contributions}

Study design: RJ, FGH, MT

Data Collection and analysis: RJ, KS, AH

Manuscript preparation: RJ, FGH, MT

All authors have read and approved the final version.

\section{Conflict of Interest}

"The authors declare that they have no competing interests."

\section{Funding}

This work was supported by Tarbiat Modares University. The funding agency did not play any role in the planning, conduct, and reporting or in the decision to submit the paper for publication.

\section{Availability of data and materials}

The datasets used and/or analyzed during this study are available from the corresponding author on reasonable request.

\section{References}

1- Moore SC, Patel AV, Matthews CE, et al. Leisure time physical activity of moderate to vigorous intensity and mortality: a large pooled cohort analysis. PLoS Medicine2012; 9(11): e1001335.

2- Rejali M, Mostajeran M. Assessment of physical activity in medical and public health students of Isfahan University of medical sciences- 2008. Health System Research2010; 6(2): 173-9.
3- Ramezani Y, Mobasheri M, Moosavi Gh, et al. Exposure rate of cardiovascular risk factors among clients of health-care clinics in Kashan, Autumn 2010. Journal of Shahrekord University of Medical Sciences2011; 13(2): 76-82.

4- Solhi M, ZinatMotlagh F, Karimzade Shirazi K, Taghdisi MH, Jalilian F. Designing and implementing educational program to promote physical activity among students: an application of the theory of planned behavior. Ofogh Danesh2013; 18(1): 45-53.

5- U.S. department of health and human services. Healthy people 2010: understanding and improving health. Washington Dc: U.S. Government Printing Office, November 2000 cited 12 Nov 2005. Available at: http://www.healthypeople.gov/2010/document/pdf/ uih/2010uih.pdf. Accessed July 16, 2017.

6- Fakhrzadeh H, Djalalinia S, Mirarefin M, et al. Prevalence of physical inactivity in Iran: a systematic review. J Cardiovasc Thorac Res2016; 8(3): 92-97.

7- Esteghamati A, Khalilzadeh O, Rashidi A, Kamgar M, Meysamie A, Abbasi M. Physical activity in Iran: results of the third national surveillance of risk factors of noncommunicable diseases (SuRFNCD-2007). J Phys Act Health2011; 8(1): 27-35.

8 -Department of risk management for noncommunicable diseases ministry of health and medical education. Provincial comparison report on the prevalence of noncommunicable risk factors (Based on national fouryear data from 2006-2009), In the Islamic Republic of Iran; 2014.

9- Mostafavi F, Pirzadeh A. Physical activity among employee women based on transtheoretical model. $J$ Educ Health Promot2015; 4(1): 81-6.

10- Jalilian F, Emdadi SH, Mirzaie M, Barati M. The survey physical activity status of employed women in Hamadan university of medical sciences: the relationship between the benefits, barriers, selfefficacy and stages of change. Toloo-e-Behdasht2011; 9(4):89-98.

11- Jalilian M, Darabi M, Sharifirad Gh, Kakaei H. Interventional program based on trans-theoretical model to promote exercises in office workers. Health System Research2013; 9(2): 188-95.

12- Chatripour R, Sadeghi Rad K, Ghazanfari Z, Jorvand R. The survey of teacher's lifestyle in dehloran boys high schools on cardiovascular disease risk factors. 2nd. International \& 6th National Iranian Congress on Health Education and Promotion. 19-21 May, 2015. Kermanshah, Iran.

13- Skelton JA, Rudolph CD. Overweight and obesity. In: Kliegman RM, Behrman RE, Jenson HB, Stanton BF, Zietell BJ, Dawis HW, eds. Nelson Textbook of pediatrics. 18th ed. Philadelphia: Saunders; 2007. pp: 232-42.

14- Aminzadeh M, Hosseinzadeh M, Nikfar R, Ghaderian $\mathrm{M}$, Mohsenpourian S. Incidence in Overweight and 
Obesity among Schoolchildren, Ahvaz-2010. Jundishapur Scientific Medical Journal2013; 12(4): 355-61.

15- Samavat T, Hojatzadeh E, Shams M, et all. Prevention and control of cardiovascular disease (for government employees). Tehran: Mehrravsh publishers; 2012.

16- Sadeghi-Bazargani H, Jafarzadeh H, Fallah M, et al. Risk factor investigation for cardiovascular health through WHO STEPS approach in Ardabil, Iran. Vasc Health Risk Manag2011; 7: 417-24.

17- Hosseinnejad M, Azhide M, Mohammad-alizade S, Hagh-doost AA. The role of self-efficacy in predicting dietary behaviors in high school students in Kerman. Journal of Shahid Sadoughi University of Medical Sciences 2001; 16(3): 49-56.

18- Glanz KA, Rimer BA, Viswanth K. Health behavior and health education theory, research and practice. San Farancisco, CA, US: Josey-Bass publisher; 2008. pp: 8-30. 19- Heidarnia E. Discussions in the process of health education. Tehran: Zamani Naser publishing; 2003. pp: 92-109.

20- Jorvand R, Tavousi M, Ghofranipour F. Impact of sport on the cardiovascular diseases scale based on health belief model: questionnaire psychometric properties. Iran Red Crescent Med J2018. In Press

21-Gaeini AA, Samadi A, Khalesi M. Fat mass index (FMI) comparing to body mass index (BMI) in the determination of obesity in preschool children. Razi Journal of Medical Sciences2014; 21(120): 53-60.

22- Golshahi J, Sadeghi M, Esteki Ghashghaei F, Roohafza $\mathrm{H}$, Pourmoghaddas A. Is rehabilitation program be more effective in obese women with CAD? Journal of Isfahan Medical School2014; 32(294): 1-7.

23- Zen V, Fuchs FD, Wainstein MV, et al. Neck circumference and central obesity are independent predictors of coronary artery disease in patients undergoing coronary angiography. Am J Cardiovasc Dis2012; 2(4): 323-30.

24- Farshadfar E. Principles and statistical methods. Volume II, 1ed. Kermanshah: Taq-e Bostan publisher; 2002. pp: 245.

25- Abdi J, Eftekhar H, Mahmoodi M, et al. The effect of theory and new communication technologiesbased lifestyle intervention on the weight control of the employees with overweight and obesity. Journal of Health Education and Health Promotion2015; 3(3): 188-97.
26- Gunstad J, Lhotsky A, Wendell CR, Ferrucci L, Zonderman AB. Longitudinal examination of obesity and cognitive function: results from the Baltimore longitudinal study of aging. Neuroepidemiology2010; 34(4): 222-9.

27- Rahimi T, Shojaei S, Mousavi Miyandashti Z, Jafary Nodoushan Z, Farahabadi M. Predictors of preventive behaviors of cardiovascular diseases: Based on health belief model in women referred to health treatment centers in Qom City, 2014, Iran. Qom University of Medical Sciences Journal2016; 9(11): 51-9.

28- Sallis JF, Prochaska JJ, Taylor WC. A review of correlates of physical activity of children and adolescents. Med Sci Sports Exerc2000; 32(5): 963-75.

29- Al-Ali N, Haddad LG. The effect of the health belief model in explaining exercise participation among Jordanian myocardial infarction patients. $J$ Transcult Nurs2004; 15(2): 114-21.

30- Sullivan KA, White KM, Young RM, Scott CJ. Predictors of intention to exercise to reduce stroke risk among people at risk of stroke: An application of an extended health belief model. Rehabilitation Psychology2008; 53(4): 505-12.

31- Vahedian-Shahroodi M, Lal Monfared E, Esmaily H, Tehrani H, Mohaddes Hakkak H. Prediction of osteoporosis preventive behaviors using the health belief model. Journal of Health Education and Health Promotion2014; 2(3): 199-207.

32- Solimanian A, Hajizadeh I, Shojaeezadeh D, Niknami SH, Tavousi M. Predictors of physical activity to prevent osteoporosis based on extended health belief model. Payesh2014; 13(3): 313-20.

34- Johnson EJ, Winett RA, Anderson ES, Clum GA, Davy BM. The relationship of environmental, social and individual factors and physical activity participation level in young adults. [dissertation]. Virginia: Virginia Polytechnic, Institute and State University, Blacksburg 2008.

35- Bandura A. Human agency in social cognitive theory. American Psychologist1989; 44(9): 1175-84.

36- Parhoodeh Y, Khezeli M, Abbasgholizadeh N. Application of trans-theoretical model in identification of physical activity behavior determinants in University students of Gilan Gharb. Journal of Health2015; 6(3): 281-90.

Copyright $₫ 2016$ ASP Ins. This open-access article is published under the terms of the Creative Commons Attribution-NonCommercial 4.0 International License which permits Share (copy and redistribute the material in any medium or format) and Adapt (remix, transform, and build upon the material) under the Attribution-NonCommercial terms. 